\title{
High-Speed Titanium Production by Magnesiothermic Reduction of Titanium Trichloride
}

\author{
Osamu Takeda*1 and Toru H. Okabe*2 \\ Institute of Industrial Science, University of Tokyo, Tokyo 153-8505, Japan
}

The possibility of a high-speed and (semi-)continuous titanium production process by the magnesiothermic reduction of titanium subchloride-titanium dichloride $\left(\mathrm{TiCl}_{2}\right)$ and/or titanium trichloride $\left(\mathrm{TiCl}_{3}\right)$ - is discussed. When the $\mathrm{TiCl}_{3}$ feed material and magnesium reductant charged into a titanium reaction container were heated at a rate of $0.056 \mathrm{~K} / \mathrm{s}(3.3 \mathrm{~K} / \mathrm{min})$ in an argon atmosphere, the temperature of the container rapidly increased above $973 \mathrm{~K}$, and the magnesiothermic reduction of $\mathrm{TiCl}_{3}$ proceeded at a high speed. After the reduction, the reaction product magnesium chloride $\left(\mathrm{MgCl}_{2}\right)$ and the excess magnesium were removed by leaching or vacuum distillation. An efficient separation process of $\mathrm{MgCl}_{2}$ from titanium metal by a combination of draining and vacuum distillation was also investigated. Under a suitable condition, titanium with $99.5 \%$ purity was efficiently obtained. The titanium reaction container showed no signs of damage, thus proving its suitability for the magnesiothermic reduction of $\mathrm{TiCl}_{3}$.

(Received September 2, 2005; Accepted January 6, 2006; Published April 15, 2006)

Keywords: titanium, titanium trichloride, magnesiothermic reduction, high-speed process, subhalide reduction process

\section{Introduction}

Titanium (Ti), which has excellent properties such as low weight, high strength, and high corrosion resistance, is commercially produced by the magnesiothermic reduction of titanium tetrachloride $\left(\mathrm{TiCl}_{4}\right)$; this is known as the Kroll process. ${ }^{1)}$ The current titanium production process has several advantages, including the production of high-purity titanium with low oxygen content obtainable. However, the Kroll process is unsuitable for the development of a continuous reduction process because titanium deposits generated in the reduction process firmly adhere to the inner wall of the steel reaction container. At present, all commercial titanium production is carried out by a labor-intensive batch-type process. Furthermore, the reduction process has to be carried out slowly in order to control the reactor temperature since the reduction of $\mathrm{TiCl}_{4}$ is a highly exothermic reaction. Therefore, the production speed of titanium by the Kroll process is extremely low; for example, it is reported to be 1.3 ton/day per reactor (10 ton batch) or 1.9 ton/day per reactor ( 7.4 ton batch) even when a large modern facility is employed. ${ }^{2,3)}$

Although the demand for titanium metal is growing annually, ${ }^{4}$ further improvement in its productivity by the Kroll process appears to be difficult. For further expansion of the applications of titanium metal, it is necessary to develop a new titanium production process with low cost and high productivity. At present, in view of developing a new process for producing low-cost titanium, direct reduction processes of titanium dioxide $\left(\mathrm{TiO}_{2}\right)$ are being actively investigated all over the world. ${ }^{5-7)}$ These new processes have the potential for producing low-cost titanium; however, several technical problems need to be resolved before a large-scale commercial process can be established. Meanwhile, a new titanium production process using chloride metallurgy is also being

\footnotetext{
${ }^{* 1}$ Graduate Student, University of Tokyo

${ }^{* 2}$ Corresponding author, E-mail: takeda@iis.u-tokyo.ac.jp or

okabe@iis.u-tokyo.ac.jp
}

investigated since it can produce high-quality titanium by using an oxygen-free system, which is an essential advantage. $^{8-12)}$

Based on the abovementioned background, the authors are developing a new high-speed and (semi-)continuous titanium production process by the magnesiothermic reduction of titanium subchloride-titanium dichloride $\left(\mathrm{TiCl}_{2}\right)$ and/or titanium trichloride $\left(\mathrm{TiCl}_{3}\right){ }^{13-15)}$ Figure 1 shows the flow of the new titanium production process, termed the subhalide

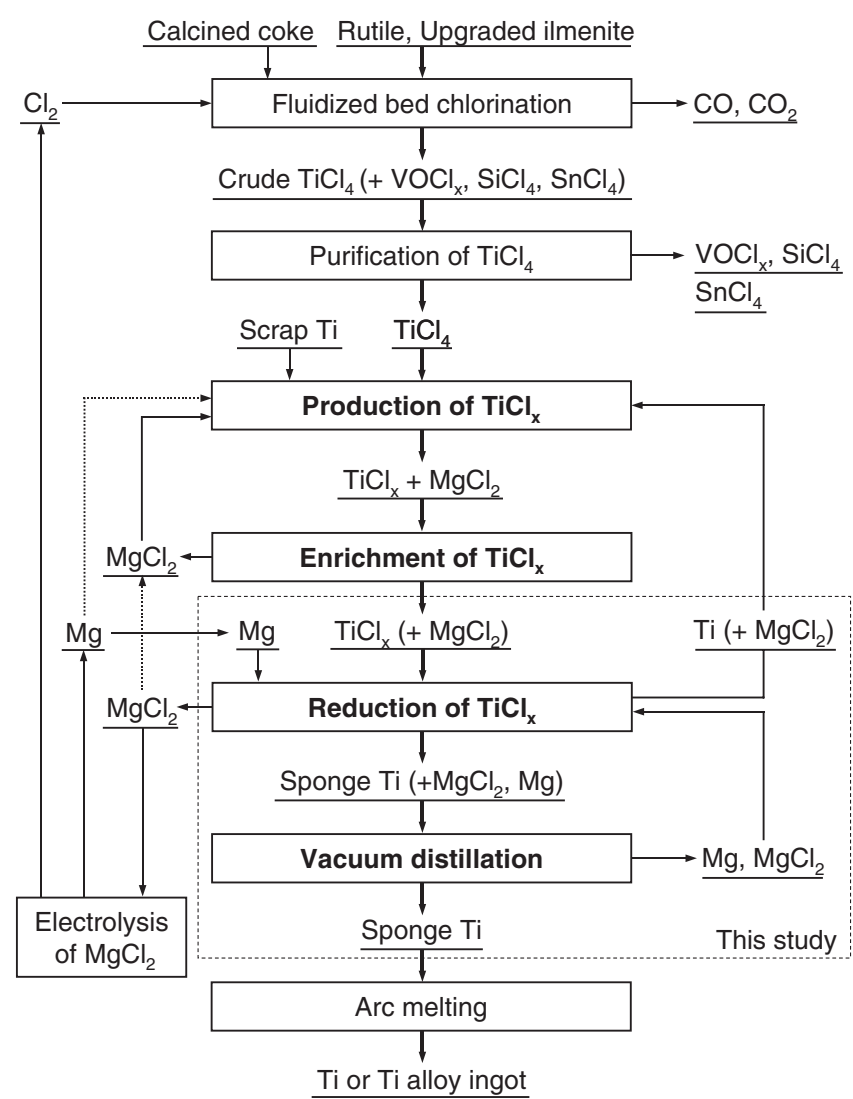

Fig. 1 Flowchart of the new titanium production process based on the subhalide reduction process. 
Table 1 Properties of titanium chlorides.

\begin{tabular}{|c|c|c|c|}
\hline Property & $\mathrm{TiCl}_{4}$ & $\mathrm{TiCl}_{3}$ & $\mathrm{TiCl}_{2}$ \\
\hline State at $293 \mathrm{~K}^{\mathrm{a})}$ & Liquid & Solid & Solid \\
\hline Color ${ }^{\mathrm{b})}$ & Clear & Red & Black \\
\hline $\begin{array}{l}\text { Molecular weight } \\
{\left[10^{-3} \mathrm{~kg} / \mathrm{mol}\right]^{\mathrm{c})}}\end{array}$ & 189.7 & 154.2 & 118.8 \\
\hline $\begin{array}{l}\text { Density at } 293 \mathrm{~K} \\
{\left[10^{3} \mathrm{~kg} / \mathrm{m}^{3}\right]^{\mathrm{b})}}\end{array}$ & 1.70 & No data & 3.13 \\
\hline $\begin{array}{l}\text { Melting point } \\
{[\mathrm{K}]^{\mathrm{a})}}\end{array}$ & $\begin{array}{c}249 \\
\left(-24^{\circ} \mathrm{C}\right)\end{array}$ & - & - \\
\hline $\begin{array}{l}\text { Boiling point } \\
{[\mathrm{K}]^{\mathrm{a})}}\end{array}$ & $\begin{array}{c}410 \\
\left(137^{\circ} \mathrm{C}\right)\end{array}$ & - & 一 \\
\hline $\begin{array}{l}\text { Sublimation point } \\
{[\mathrm{K}]^{\mathrm{a})}}\end{array}$ & - & $\begin{array}{c}1103 \\
\left(830^{\circ} \mathrm{C}\right)\end{array}$ & $\begin{array}{c}1580 \\
\left(1307^{\circ} \mathrm{C}\right)\end{array}$ \\
\hline $\begin{array}{l}\Delta G^{\circ} \text { f at } 1073 \mathrm{~K} \\
{\left[\mathrm{~kJ} / \mathrm{mol} \mathrm{Cl}_{2}\right]^{\mathrm{a})}}\end{array}$ & -317 & -327 & -344 \\
\hline $\begin{array}{l}\Delta G^{\prime \circ} \text { at } 1073 \mathrm{~K} \\
{[\mathrm{~kJ} / \mathrm{mol} \mathrm{Ti}]^{\mathrm{a})}}\end{array}$ & -637 & -491 & -344 \\
\hline $\begin{array}{l}\text { Vapor pressure } \\
\text { at } 1073 \mathrm{~K}[\mathrm{~Pa}]^{\mathrm{a})}\end{array}$ & 一 & $\begin{array}{l}7.5 \times 10^{4} \\
(0.74 \mathrm{~atm})\end{array}$ & $\begin{array}{c}12 \\
\left(1.2 \times 10^{-4} \mathrm{~atm}\right)\end{array}$ \\
\hline
\end{tabular}

a) I. Barin: Thermochemical Data of Pure Substances, (VCH Verlagsgesellschaft mbH, Weinheim, Germany, 1989), pp. 1531-1533.

b) M. Nakahara: Dictionary of Inorganic Compounds \& Complexes, (Koudansya, Tokyo, 1997) p. 87.

c) S. Nagasaki et al.: Kinzoku Data Book, 3rd ed., (ed. by Japan Inst. Metals, Maruzen, Tokyo, 1993) pp. 1-11.

reduction process, while the physical and chemical properties of titanium subchloride are summarized in Table $1 .{ }^{16-18)}$ As shown in the figure, the $\mathrm{TiCl}_{4}$ feed is converted to titanium subchloride, $\operatorname{TiCl}_{x}(x=2,3)$, by its reaction with magnesium $(\mathrm{Mg})$ or titanium scraps. ${ }^{19)}$ When these subchlorides are synthesized in a molten magnesium chloride $\left(\mathrm{MgCl}_{2}\right)$ medium, the generated $\mathrm{TiCl}_{x}$ is subsequently enriched in the medium by utilizing the temperature dependence of solubility to $\mathrm{TiCl}_{x}$ in $\mathrm{MgCl}_{2} .{ }^{20)}$ The mixture of $\mathrm{MgCl}_{2}$ and $\mathrm{TiCl}_{x}$ is then loaded into a titanium reaction container, and the $\mathrm{TiCl}_{x}$ is reduced by magnesium. After the reduction, the reaction product $\mathrm{MgCl}_{2}$ and excess magnesium are removed and recovered by draining and vacuum distillation.

The utilization of subchloride as the feed material has the following advantages: (1) The speed of the reduction process can be increased and a (semi-)continuous process can be designed because the heat produced by the reduction of subchloride is substantially lower than that of $\mathrm{TiCl}_{4}$ as shown in following equations. ${ }^{16)}$

$$
\begin{aligned}
\operatorname{TiCl}_{4}(g)+2 \mathrm{Mg}(l) & =\mathrm{Ti}(s)+2 \mathrm{MgCl}_{2}(l): \\
\Delta H_{\mathrm{f}}^{\circ} & =-433 \mathrm{~kJ} \text { at } 1000 \mathrm{~K} \\
\mathrm{TiCl}_{3}(s)+3 / 2 \mathrm{Mg}(l) & =\mathrm{Ti}(s)+3 / 2 \mathrm{MgCl}_{2}(l): \\
\Delta H_{\mathrm{f}}^{\circ} & =-187 \mathrm{~kJ} \text { at } 1000 \mathrm{~K} \\
\mathrm{TiCl}_{2}(s)+\mathrm{Mg}(l) & =\mathrm{Ti}(s)+\operatorname{MgCl}_{2}(l): \\
\Delta H_{\mathrm{f}}^{\circ} & =-91 \mathrm{~kJ} \text { at } 1000 \mathrm{~K}
\end{aligned}
$$

In addition, the heat extraction ratio can be drastically increased by conducting the reduction process in the condensed phase in the absence of the gas phase. (2) The iron contamination of the titanium product can be avoided since metallic titanium, which can never be used in the Kroll
Table 2 Materials used in this study.

\begin{tabular}{ccc}
\hline Materials & Form & $\begin{array}{c}\text { Purity or concentration } \\
\text { (mass\%) }\end{array}$ \\
\hline $\mathrm{TiCl}_{3}$ mixture $^{\mathrm{a})}$ & Powder & $77.6^{\mathrm{c})}$ \\
$\mathrm{Mg}^{\text {b) }}$ & Ingot & 99.9 up \\
\hline
\end{tabular}

a) Supplied by Toho Titanium Co., Ltd.

b) Supplied by Hirano Seizaemon Co., Ltd.

c) Balance component is $\mathrm{AlCl}_{3}$.

process, can be utilized as the reactor material under $\mathrm{Ti} /$ $\mathrm{TiCl}_{2}$ equilibrium. (3) The reaction product $\mathrm{MgCl}_{2}$ can be easily removed by vacuum distillation and high-purity titanium can be obtained. (4) This process is suitable for a small-scale (semi-)continuous process, and the crushing of massive sponge is unnecessary when the size of the reactor is reduced; the obtained titanium can be melted and cast into an ingot directly after the vacuum distillation. Furthermore, by effectively using titanium scraps, the new process can be made environment-friendly.

In this article, fundamental research including the experiment for the magnesiothermic reduction of $\mathrm{TiCl}_{3}$ for establishing the new titanium production process is discussed.

\section{Experimental}

\subsection{Magnesiothermic reduction of titanium trichloride by using a titanium reaction container}

The materials used in this study are listed in Table 2. Since catalyst-grade $\mathrm{TiCl}_{3}$ feed powder produced by the aluminothermic reduction of $\mathrm{TiCl}_{4}$ is used in this study, it contains aluminum trichloride $\left(\mathrm{AlCl}_{3}\right)$ as an impurity. The $\mathrm{AlCl}_{3}$ in the feed was removed by sublimation (sublimation point: $454 \mathrm{~K})^{16)}$ during the period when the temperature increased before the reduction experiment.

Schematic illustrations of the experimental apparatus are shown in Fig. 2, and the experimental conditions are listed in Table 3. In Exp. A and B, a specially fabricated titanium reaction container $(99.9 \%, \phi 19 \mathrm{~mm}$ outer diameter, $45 \mathrm{~mm}$ height, $1 \mathrm{~mm}$ thickness) with a titanium foil lining $(99.9 \%$, $0.1 \mathrm{~mm}$ thickness) was inserted into a stainless steel cell (SUS304, $\phi 20 \mathrm{~mm}$ outer diameter, $80 \mathrm{~mm}$ height, $0.3 \mathrm{~mm}$ thickness). In Exp. C, a stainless steel cell with a stainless steel foil lining (SUS304, $0.1 \mathrm{~mm}$ thickness) was used as the reaction container instead of the titanium reaction container. In Exp. D and E, a specially fabricated large-sized titanium reaction container $(99.9 \%$, octagonal pillar shape, $\phi 52 \mathrm{~mm}$ outer diameter, $85 \mathrm{~mm}$ height, $0.2 \mathrm{~mm}$ thickness) was used.

A lump of magnesium metal (99.95\%, 4.01-4.05 g) was loaded into each reaction container (Exp. A-C). In Exp. D, a lump of magnesium metal $(22.10 \mathrm{~g})$ was placed at the bottom of the reaction container, and in Exp. E, a magnesium metal rod $(22.52 \mathrm{~g})$ was set vertically in the reaction container. $\mathrm{TiCl}_{3}$ powder (19.70-101.6 g) was loaded into the reaction container holding the magnesium metal in a glove box $\left(\mathrm{O}_{2}\right.$ and $\mathrm{H}_{2} \mathrm{O}$ levels were maintained below $1 \mathrm{ppm}$ ), and the container was placed inside a stainless steel vessel (SUS316, $60 \mathrm{~mm}$ outer diameter, $90 \mathrm{~mm}$ height). Subsequently, the stainless steel vessel, which was connected to a stainless steel 
(a)

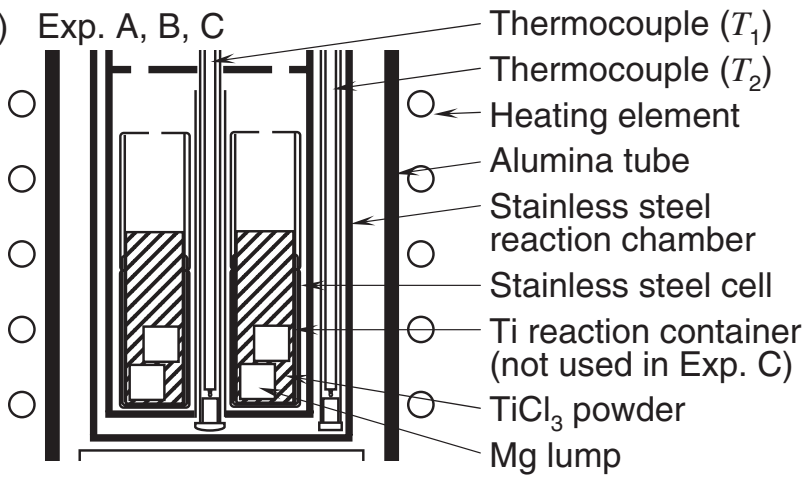

(b) Exp. D

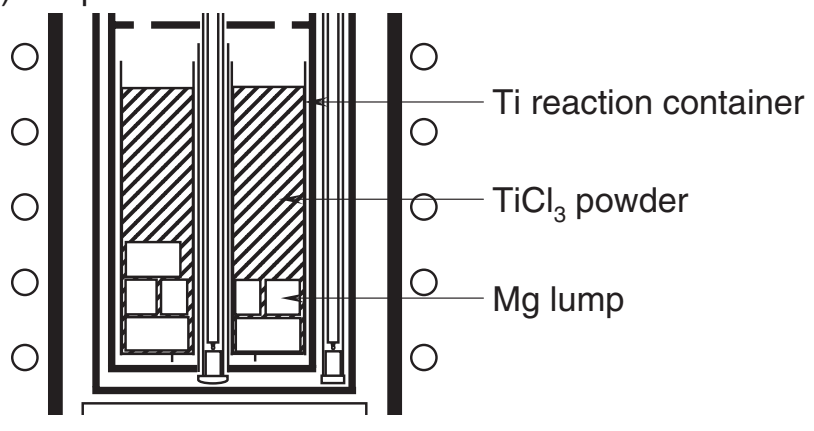

(c) Exp. E

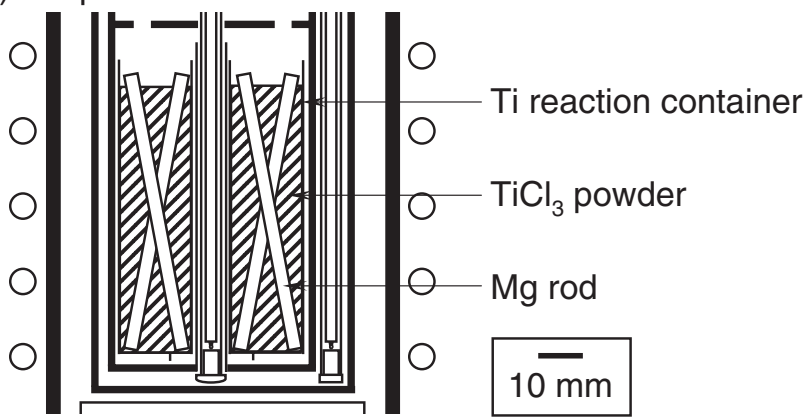

Fig. 2 Schematic illustrations of the experimental apparatus for the magnesiothermic reduction of $\mathrm{TiCl}_{3}$ (one end closed type). The inner setup of the reaction vessel. (a) Exp. A, B, and C; (b) Exp. D; (c) Exp. E.

condenser, was placed in a gas-tight stainless steel chamber filled with argon gas. Thermocouples were then placed at the center of (inside temperature, $T_{1}$ ) and outside (outside temperature, $T_{2}$ ) the reaction container. The container was heated to $1073 \mathrm{~K}$ at a rate of $0.056 \mathrm{~K} / \mathrm{s}(3.3 \mathrm{~K} / \mathrm{min})$, and the temperature change during the experiment was monitored.

After the magnesiothermic reduction of $\mathrm{TiCl}_{3}$ was complete, the container was maintained at $1073 \mathrm{~K}$ for $0.6 \mathrm{ks}$ (10 min), and the experiment was terminated (Exp. A, D, and E). The container was cooled down to ambient temperature, and the sample in the container was mechanically recovered. The obtained sample was immersed in distilled water for $86 \mathrm{ks}(24 \mathrm{~h})$, in acetic acid for $86 \mathrm{ks}(24 \mathrm{~h})$, and in hydrochloric acid for $1.8 \mathrm{ks}(0.5 \mathrm{~h})$ to dissolve and remove the reaction product $\mathrm{MgCl}_{2}$ and excess magnesium. The titanium sponge deposit obtained after the leaching was rinsed with distilled water, alcohol, and acetone, and finally dried in vacuum for analysis.

In Exp. B and C, the container was maintained at $1073 \mathrm{~K}$
Table 3 Experimental conditions for the magnesiothermic reduction of $\mathrm{TiCl}_{3} \cdot{ }^{\text {a) }}$

\begin{tabular}{|c|c|c|c|c|}
\hline \multirow{2}{*}{$\begin{array}{l}\text { Exp. } \\
\text { No. }\end{array}$} & \multicolumn{2}{|c|}{ Mass of sample } & \multirow{2}{*}{$\begin{array}{c}\text { Molar ratio, } \\
n_{\mathrm{Mg}} / n_{\mathrm{TiCl}_{3}}\end{array}$} & \multirow{2}{*}{$\begin{array}{c}\text { Removal methoc } \\
\text { of by-product }\end{array}$} \\
\hline & $\begin{array}{c}\mathrm{TiCl}_{3} \text { mix., } \\
w_{\mathrm{TiCl}_{3}} / \mathrm{g}\end{array}$ & $\begin{array}{c}\mathrm{Mg} \\
w_{\mathrm{Mg}} / \mathrm{g}\end{array}$ & & \\
\hline A & 19.70 & 4.01 & 1.65 & Leaching \\
\hline $\mathrm{B}$ & 19.76 & 4.02 & 1.65 & Evaporation \\
\hline $\mathrm{C}^{\mathrm{b})}$ & 19.89 & 4.04 & 1.65 & Evaporation \\
\hline $\mathrm{D}$ & 99.43 & 22.10 & 1.80 & Leaching \\
\hline $\mathrm{E}$ & 101.65 & 22.52 & 1.80 & Leaching \\
\hline $\mathrm{X}$ & 100.95 & 20.56 & 1.65 & Evaporation \\
\hline $\mathrm{Y}$ & 99.96 & 22.25 & 1.80 & Evaporation \\
\hline
\end{tabular}

a) Furnace temperature was held at $1073 \mathrm{~K}$ for about $600 \mathrm{~s}$ after the magnesiothermic reduction of $\mathrm{TiCl}_{3}$.

b) Stainless steel reaction container was used instead of titanium reaction container in this experiment.

for $0.6 \mathrm{ks}(10 \mathrm{~min})$ after the completion of the magnesiothermic reduction of $\mathrm{TiCl}_{3}$, and the stainless steel chamber was evacuated to below $20 \mathrm{~Pa}\left(2 \times 10^{-4} \mathrm{~atm}\right)$. Subsequently, the reaction container was heated to $1273 \mathrm{~K}$ at a rate of $0.056 \mathrm{~K} / \mathrm{s}$ $(3.3 \mathrm{~K} / \mathrm{min})$ in order to remove the reaction product $\mathrm{MgCl}_{2}$ and excess magnesium by evaporation. After the temperature reached $1273 \mathrm{~K}$, the experiment was terminated. The container was cooled down to ambient temperature, and the sample in the container was mechanically recovered for analysis.

\subsection{Separation process by a combination of draining and vacuum distillation}

Schematic illustrations of the experimental apparatus for studying the feasibility of the in-situ separation process by a combination of draining and vacuum distillation after the subhalide reduction are shown in Fig. 3. The representative experimental conditions are listed as Exp. $\mathrm{X}$ and $\mathrm{Y}$ in Table 3. A titanium reaction container identical to that used in Exp. D and $\mathrm{E}$ was pitted for draining the reaction product $\mathrm{MgCl}_{2}$ and placed inside a stainless steel vessel. A stainless steel plug and an outlet port for draining the reaction product $\mathrm{MgCl}_{2}$ and excess magnesium after the reduction were placed beneath the stainless steel vessel.

$\mathrm{TiCl}_{3}$ powder $(99.96-100.95 \mathrm{~g})$ in a glove box was loaded into the titanium reaction container in which a magnesium metal rod (20.56-22.25 g) was set vertically. Subsequently, the stainless steel vessel connected to a stainless steel condenser was placed in a gas-tight stainless steel chamber filled with argon gas. The container was heated to $1073 \mathrm{~K}$ at a rate of $0.056 \mathrm{~K} / \mathrm{s}(3.3 \mathrm{~K} / \mathrm{min})$, and the temperature change during the experiment was monitored using the same method as in Exp. D and E.

After the magnesiothermic reduction of $\mathrm{TiCl}_{3}$ was complete, the container was maintained at $1073 \mathrm{~K}$ for $0.6 \mathrm{ks}$ (10 min), and the outlet port was opened to drain the reaction product $\mathrm{MgCl}_{2}$ and excess magnesium into a stainless steel tray placed at the bottom of the reaction chamber. After removing $\mathrm{MgCl}_{2}(+\mathrm{Mg})$ by draining from the reaction container containing the titanium products, the stainless steel chamber was evacuated to below $20 \mathrm{~Pa}\left(2 \times 10^{-4} \mathrm{~atm}\right)$ and heated to $1273 \mathrm{~K}$ at a rate of $0.056 \mathrm{~K} / \mathrm{s}(3.3 \mathrm{~K} / \mathrm{min})$. When 
(a)

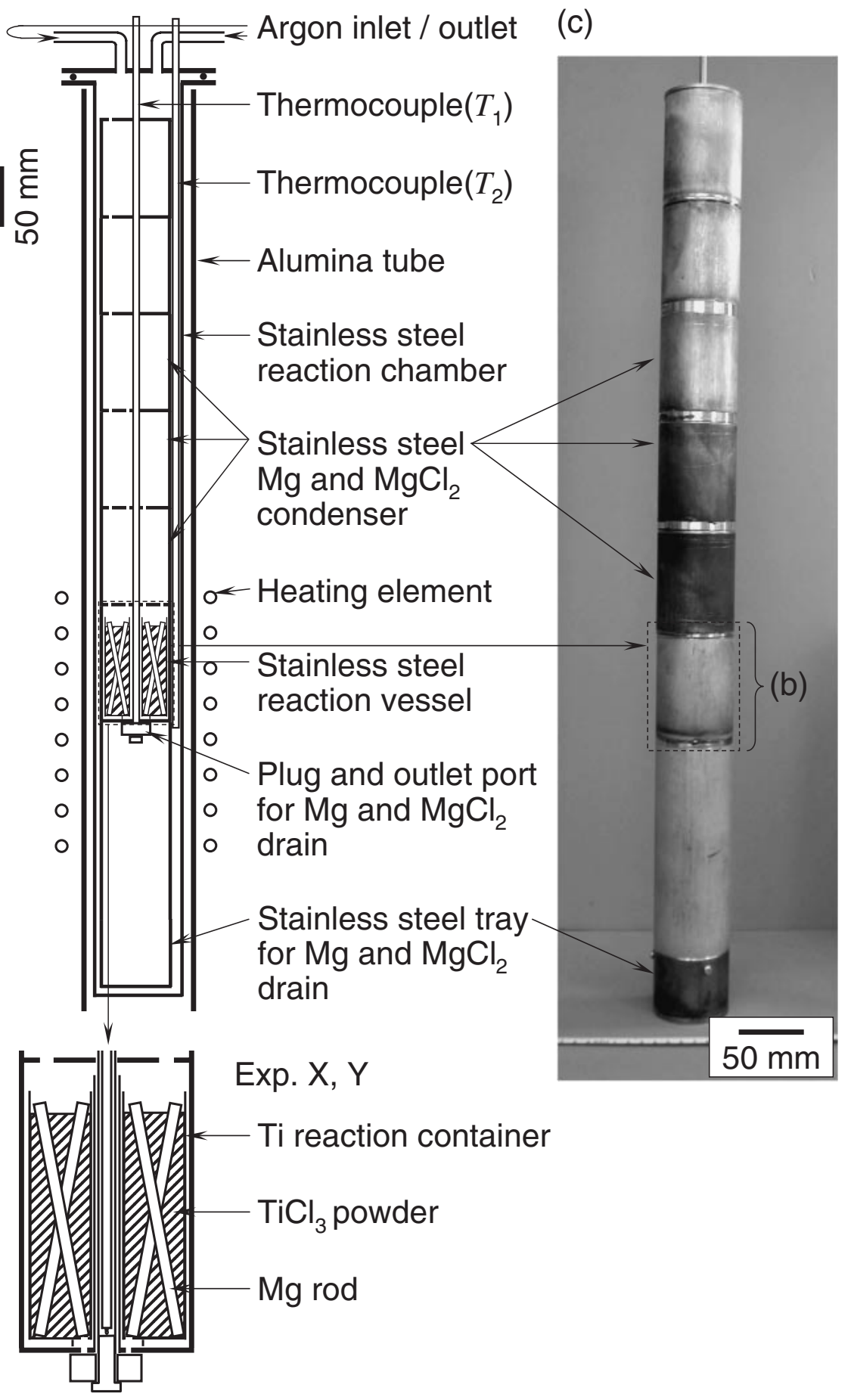

Fig. 3 Schematic illustrations of the experimental apparatus used for the magnesiothermic reduction of $\mathrm{TiCl}_{3}$ (both ends open/ $\mathrm{MgCl}_{2}$ drain type). (a) Overall appearance, (b) inner setup of reaction vessel, (c) photograph (Exp. Y).

the temperature reached $1273 \mathrm{~K}$, the experiment was terminated. $\mathrm{MgCl}_{2}$ and the excess magnesium that remained in the reaction container after the draining were removed by vacuum distillation. The container was cooled down to ambient temperature, and the sample in the container was mechanically recovered for analysis.

\subsection{Analysis}

The phases in the sample were identified by X-ray diffraction analysis (XRD). In order to prevent the $\mathrm{TiCl}_{3}$ feed powder from reacting with moisture in air, it was covered with a polyimide film in a glove box and then analyzed by XRD. The composition of the sample was determined by X-ray fluorescence analysis (XRF), and the morphology of the sample was observed by scanning electron microscopy (SEM).

\section{Results and Discussion}

3.1 Magnesiothermic reduction of titanium trichloride by using a titanium reaction container

In all the experiments, the sample temperature $T_{1}$ 
(a) Reduction (Exp. B)

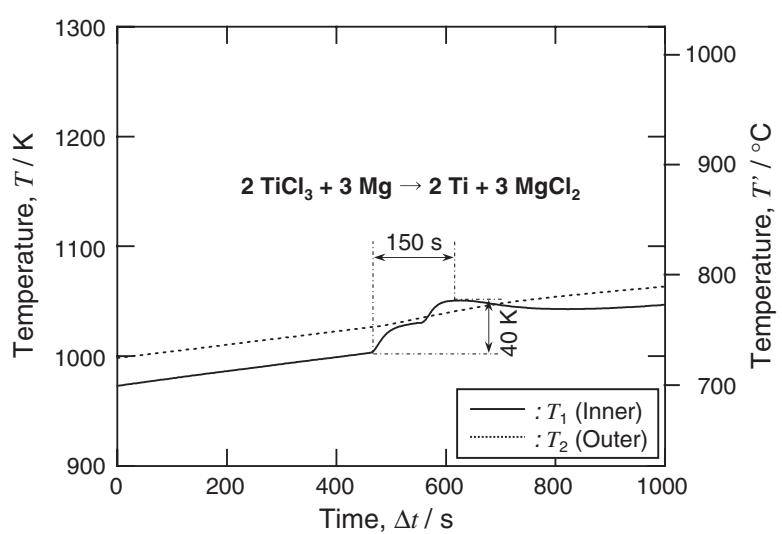

(b) Reduction (Exp. Y)

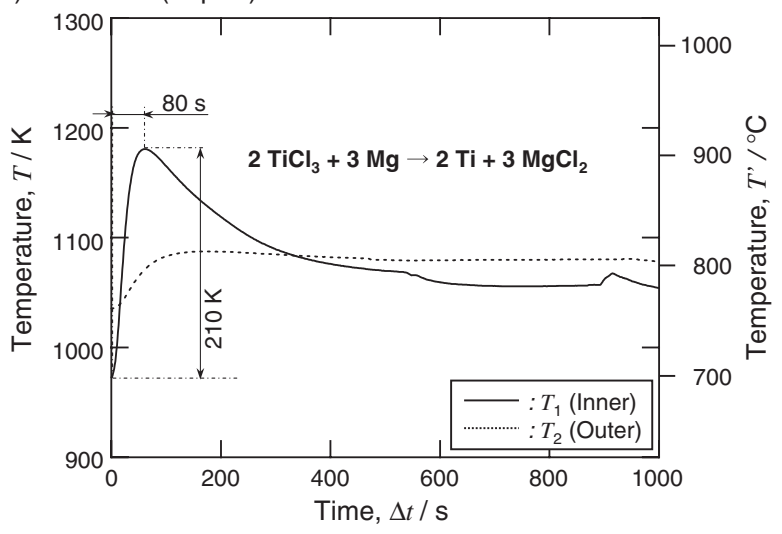

Fig. 4 Temperature change during the experiment for the magnesiothermic reduction of $\mathrm{TiCl}_{3}$. (a) Exp. B, (b) Exp. Y.

monotonically increased until it reached 973 K. Figure 4(a) shows the result of the change in the sample temperature after it reached $973 \mathrm{~K}$ in Exp. B. As shown in this figure, the sample temperature $T_{1}$ rapidly increased at $1005 \mathrm{~K}$ with a two-step rise and then decreased. The changes in the sample temperature in Exp. A and C were identical to those in Exp. B. These results indicate that the exothermic magnesiothermic reduction of $\mathrm{TiCl}_{3}$ proceeded rapidly within $200 \mathrm{~s}$.

In Exp. $\mathrm{D}$ and $\mathrm{E}$, the sample temperature $T_{1}$ rapidly increased at 993 and $1010 \mathrm{~K}$, respectively, with a one-step rise. The rates of the temperature increase during the magnesiothermic reduction of $\mathrm{TiCl}_{3}$ in Exp. D and $\mathrm{E}$ were higher than those in Exp. A-C.

Since the method for supplying feed material into the reaction container in the Kroll process is entirely different from that in the process discussed in this study, a comparison of the rates of formation of titanium deposits in these methods is difficult. However, it is important to try and compare the nominal reduction speed.

Shimosaki and Kuramoto ${ }^{21)}$ studied the rate of formation of titanium sponge in the reduction process of the Kroll process using a laboratory-scale impulse response method. The maximum speed of the magnesiothermic reduction of $\mathrm{TiCl}_{4}$ was determined to be approximately $0.006 \mathrm{~kg} / \mathrm{m}^{2} \cdot \mathrm{s}$ at $1000 \mathrm{~K}$ or $0.013 \mathrm{~kg} / \mathrm{m}^{2} \cdot \mathrm{s}$ at $1140 \mathrm{~K}$ when $\mathrm{TiCl}_{4}$ feed was supplied from the top of the reduction chamber filled with molten magnesium (cross-sectional area of the reactor: (a) Distillation (Exp. B)

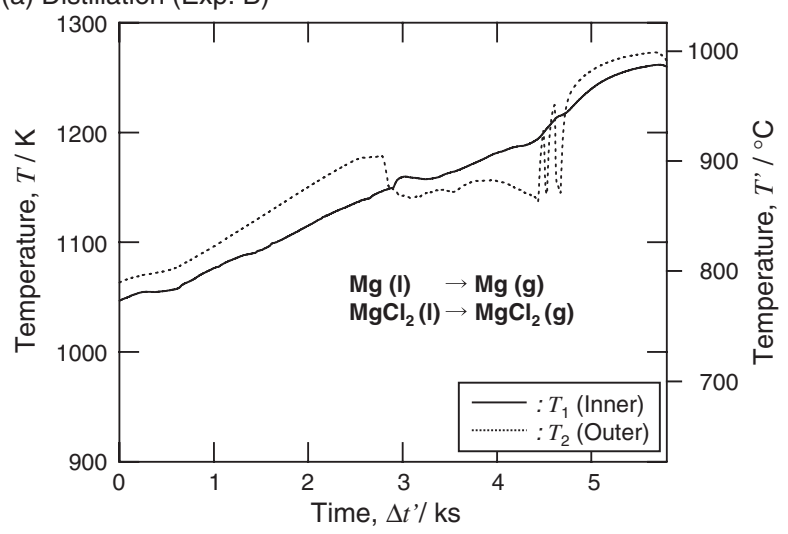

(b) Distillation (Exp. Y)

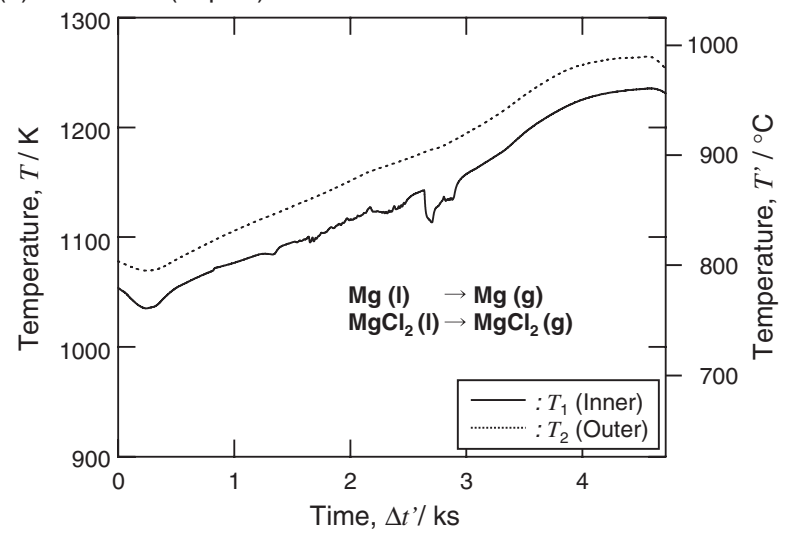

Fig. 5 Temperature change during the removal process for reaction product $\mathrm{MgCl}_{2}$ and excess magnesium by vacuum distillation. (a) Exp. B, (b) Exp. Y.

$\left.3.3 \times 10^{-3} \mathrm{~m}^{2}\right) .{ }^{21)}$ Based on the report, the nominal reduction speed per unit volume in the Kroll process is estimated to be $0.06 \mathrm{~kg} / \mathrm{m}^{3} \cdot \mathrm{s}$ at $1000 \mathrm{~K}$ or $0.13 \mathrm{~kg} / \mathrm{m}^{3} \cdot \mathrm{s}$ at $1140 \mathrm{~K}$ by assuming the volume of the reactor to be $3.3 \times 10^{-4} \mathrm{~m}^{3}$.

In a large-scale study ( 1.4 ton batch, cross-sectional area of reactor: $0.99 \mathrm{~m}^{2}$ ), the rate of formation of titanium sponge in the reduction process of the Kroll process was determined to be approximately $0.009 \mathrm{~kg} / \mathrm{m}^{2} \cdot \mathrm{s}$ (information on the operation temperature was not provided). ${ }^{22)}$ Based on the report, the nominal reduction speed per unit volume in the Kroll process is estimated to be $0.009 \mathrm{~kg} / \mathrm{m}^{3} \cdot \mathrm{s}$ by assuming the volume of the reactor to be $1.0 \mathrm{~m}^{3}$.

In this study, the magnesiothermic reduction of $\mathrm{TiCl}_{3}$ was completed in $200 \mathrm{~s}$, and the rate of formation of titanium deposit under suitable conditions (volume of reactor: $2.3 \times$ $10^{-4} \mathrm{~m}^{3}$ ) in this process is calculated to be $0.54 \mathrm{~kg} / \mathrm{m}^{3} \cdot \mathrm{s}$ at $1000 \mathrm{~K}$. From this result, the rate of formation of titanium deposits per unit area in this process is calculated to be $0.043 \mathrm{~kg} / \mathrm{m}^{2} \cdot \mathrm{s}$ (cross-sectional area of reactor: $2.8 \times 10^{-3}$ $\mathrm{m}^{2}$ ). This value is very high in comparison with that obtained in the Kroll process and this process is probably suitable for a high-speed reduction process.

In Exp. B and C, after the magnesiothermic reduction of $\mathrm{TiCl}_{3}$ was completed, the reaction product $\mathrm{MgCl}_{2}$ and excess magnesium were removed by vacuum distillation. The change in the sample temperature during the separation process for $\mathrm{MgCl}_{2}$ and excess magnesium in Exp. B are 
(a) Exp. A

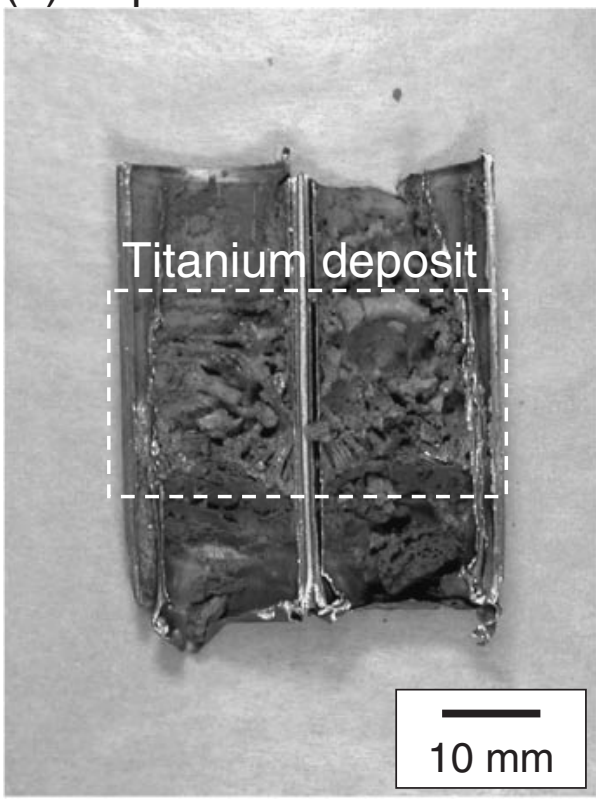

(c) Exp. D

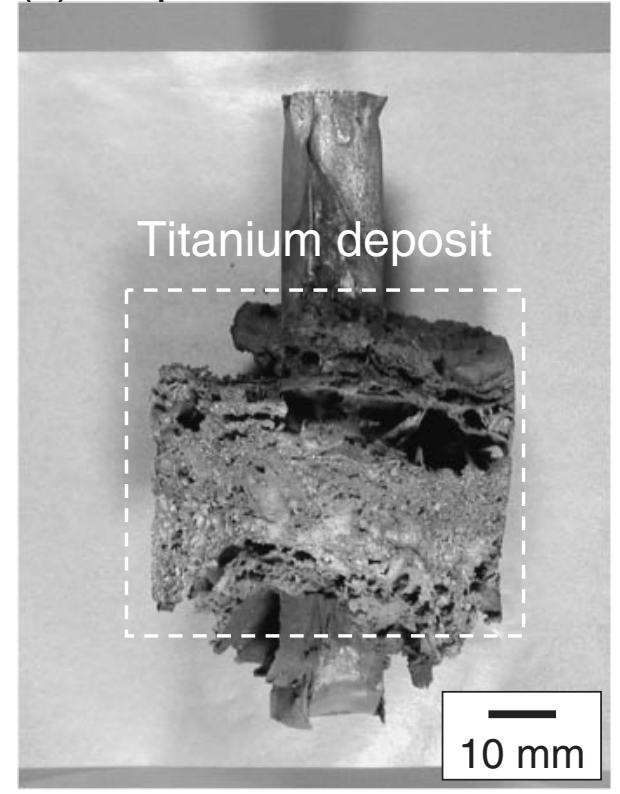

(b) Exp. B

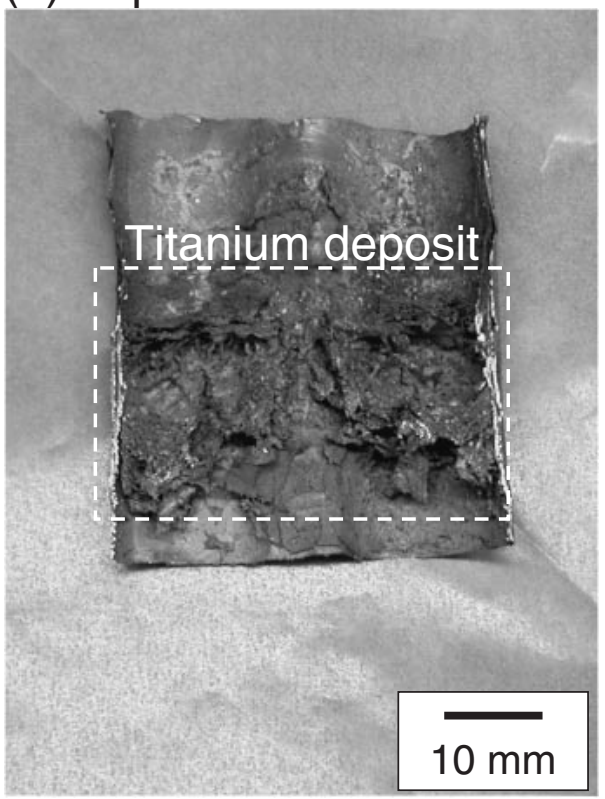

(d) Exp. E

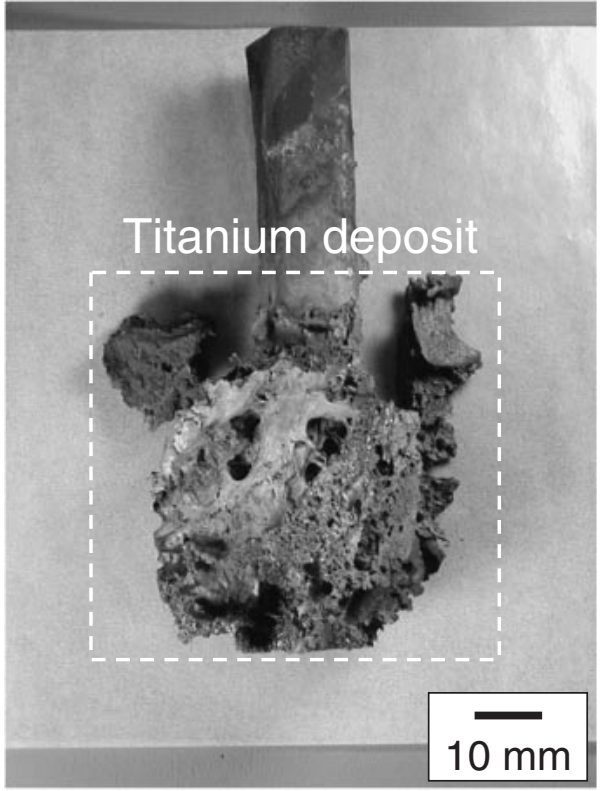

Fig. 6 Photographs of sectioned titanium reaction container after the experiment for the magnesiothermic reduction of TiCl 3 : (a) Exp. A, (b) Exp. B. Photographs of the titanium block obtained after the experiment for the magnesiothermic reduction of $\mathrm{TiCl}_{3}$ : (c) Exp. $\mathrm{C}$, (d) Exp. D.

shown in Fig. 5(a). As shown in this figure, the sample temperature gradually increased during the separation process in a fluctuating manner. The drop in temperature probably results from heat loss due to the evaporation of the $\mathrm{MgCl}_{2}$ and excess magnesium from the reaction container.

After the experiment, the stainless steel chamber was cooled down to ambient temperature and opened in air. In Exp. A, D, and E, it was observed that there were no deposits on the stainless steel condenser after the experiment, and all the reactants were confined to the reaction container. In Exp. $\mathrm{B}$ and $\mathrm{C}$, a white solid deposit and a metallic deposit were observed on the stainless steel condenser; these were identified as $\mathrm{MgCl}_{2}$ and magnesium by XRD, respectively. These results indicate that the reaction product $\mathrm{MgCl}_{2}$ and excess magnesium were removed from the reaction container by vacuum distillation and were recovered from the condenser.

In Exp. A, the titanium reaction container was recovered and vertically sectioned into two pieces where the metallic deposit and white powder were observed. Figure 6(a) shows the sectioned titanium reaction container holding porous metal deposit after leaching. It is worth noting that the titanium reaction container was not damaged after the reduction experiment and had retained its original shape. 
This was also observed in all the experiments described below. This result reveals that titanium reaction containers can be applicable to the reduction process based on the magnesiothermic reduction of $\mathrm{TiCl}_{3}$. According to the reaction in eq. (4), $\mathrm{TiCl}_{3}$ reacts with metallic titanium, and it may cause damage on titanium container. The experimental results, however, showed no damage on the titanium container. This is probably due to the fact that the reaction (4) is slower than reaction (5) under the condition employed in this study.

$$
\begin{aligned}
\operatorname{TiCl}_{3}(s)+1 / 2 \mathrm{Ti}(s) & =3 / 2 \mathrm{TiCl}_{2}(s): \\
\Delta G_{\mathrm{f}}^{\circ} & =-27 \mathrm{~kJ} \text { at } 1000 \mathrm{~K} \\
\operatorname{TiCl}_{3}(s)+3 / 2 \mathrm{Mg}(l) & =\mathrm{Ti}(s)+3 / 2 \mathrm{MgCl}_{2}(l): \\
\Delta G_{\mathrm{f}}^{\circ} & =-218 \mathrm{~kJ} \text { at } 1000 \mathrm{~K}
\end{aligned}
$$

In Exp. B, the titanium reaction container was recovered and vertically sectioned into two pieces. Figure 6(b) shows the sectioned titanium container without leaching. As shown in this figure, only a metallic deposit was observed in the container. This result indicates that the reaction product $\mathrm{MgCl}_{2}$ and excess magnesium were removed from the reaction container by vacuum distillation. The form of the deposit obtained from the titanium reaction container in Exp. $\mathrm{C}$ was similar to that in Exp. B.

In some experiments, a black powder was observed on the porous metallic deposit in the titanium reaction container after the experiment; this was identified as $\mathrm{TiCl}_{2}$ by XRD (Exp. D). This incomplete reduction is probably due to the blockage of the magnesium supply pathway. The titanium deposit generated in the middle of the container may block the reductant flow from the bottom to the top of the container; therefore, sufficient reduction of the $\mathrm{TiCl}_{3}$ feed at the top part of the container did not occur. Figure 6(c) shows the porous metallic deposit recovered from the titanium reaction container after leaching. In Exp. E, $\mathrm{TiCl}_{2}$ was not observed on the porous metallic deposit generated in the titanium reaction container. This result indicates that the magnesium metal rod placed vertically in the container was suitable for supplying the reductant to the $\mathrm{TiCl}_{3}$ feed in all parts of the container and the reduction of the $\mathrm{TiCl}_{3}$ feed to metallic titanium was successfully completed. These results indicate that the pathway for supplying magnesium reductant to the $\mathrm{TiCl}_{3}$ feed and the distribution of the magnesium reductant in the reaction container are important for facilitating the reduction process using subhalides. Figure 6(d) shows the deposit recovered from the titanium reaction container after leaching. As shown in the figure, some pieces of the porous metal deposit were obtained.

The XRD patterns of the $\mathrm{TiCl}_{3}$ feed powder and the deposit obtained after the experiment without leaching in Exp. B are shown in Figs. 7(b) and (c), respectively. Only $\alpha-$ titanium was successfully obtained in Exp. B and C. In Exp. $\mathrm{A}, \mathrm{D}$, and $\mathrm{E}, \alpha$-titanium was obtained with a trace of titanium hydride, which may have formed during the leaching process.

The analytical results of the titanium samples obtained after the experiment are listed in Table 4. As shown in this

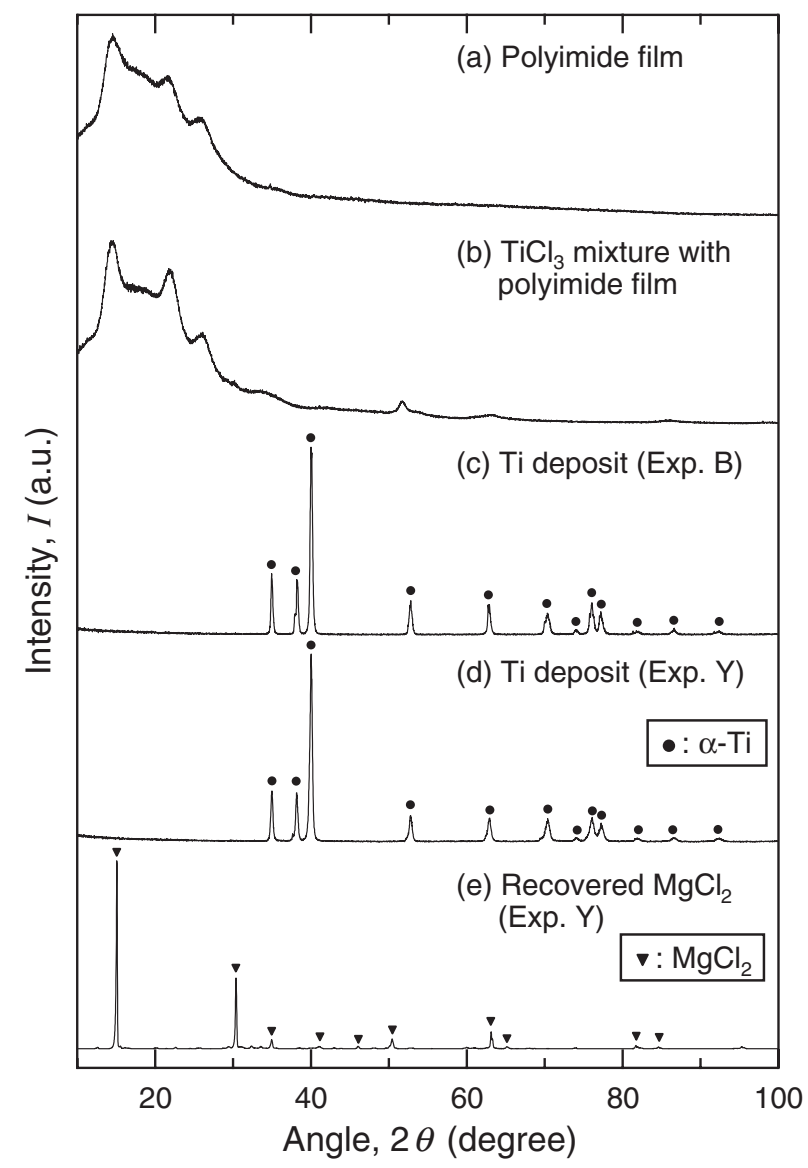

Fig. 7 X-ray diffraction patterns of the obtained samples: (a) polyimide film, (b) $\mathrm{TiCl}_{3}$ mixture covered by polyimide film, (c) titanium deposit obtained after reduction (Exp. B), (d) titanium deposit obtained after

\begin{tabular}{|c|c|c|c|c|c|c|c|c|}
\hline \multirow{2}{*}{$\begin{array}{l}\text { Exp. } \\
\text { No. }\end{array}$} & \multirow{2}{*}{$\begin{array}{l}\text { Mass, } \\
w_{\mathrm{Ti}} / \mathrm{g}\end{array}$} & \multirow{2}{*}{$\begin{array}{l}\text { Yield } \\
(\%)\end{array}$} & \multicolumn{6}{|c|}{ Concentration of element $i$ in obtained Ti sample, $C_{i}(\operatorname{mass} \%)^{\mathrm{a})}$} \\
\hline & & & $\mathrm{Ti}$ & $\mathrm{Fe}$ & $\mathrm{Ni}$ & $\mathrm{Cr}$ & $\mathrm{Mg}$ & $\mathrm{Al}$ \\
\hline A & 3.89 & 81 & 96.35 & 0.13 & $<0.01$ & 0.03 & 0.02 & 3.47 \\
\hline B & 4.74 & 99 & 99.37 & 0.16 & $<0.01$ & 0.02 & 0.16 & 0.44 \\
\hline $\mathrm{C}$ & 3.86 & 80 & 95.79 & 1.74 & 0.33 & 0.36 & $<0.01$ & 1.77 \\
\hline $\mathrm{D}$ & 15.87 & 66 & $99.26^{\mathrm{b})}$ & $0.29^{\mathrm{b})}$ & $<0.01^{\mathrm{b})}$ & $<0.01^{\text {b) }}$ & $0.10^{\mathrm{b})}$ & $0.36^{\mathrm{b})}$ \\
\hline $\mathrm{E}$ & 22.48 & 91 & $99.52^{\mathrm{b})}$ & $0.12^{\mathrm{b})}$ & $<0.01^{\text {b) }}$ & $<0.01^{\text {b) }}$ & $0.11^{\mathrm{b})}$ & $0.24^{\mathrm{b})}$ \\
\hline $\mathrm{X}$ & 19.99 & 82 & $99.04^{b)}$ & $0.18^{\mathrm{b})}$ & $0.02^{\mathrm{b})}$ & $0.02^{\mathrm{b})}$ & $0.09^{\mathrm{b})}$ & $0.65^{b)}$ \\
\hline $\mathrm{Y}$ & 21.13 & 87 & $99.18^{\mathrm{b})}$ & $0.50^{\mathrm{b})}$ & $<0.01^{\mathrm{b})}$ & $0.01^{\mathrm{b})}$ & $0.09^{\mathrm{b})}$ & $0.21^{b)}$ \\
\hline
\end{tabular}
reduction (Exp. Y), (e) $\mathrm{MgCl}_{2}$ recovered by distillation. XRD reference pattern: $\alpha$-Ti: PDF \#44-1294, $\mathrm{MgCl}_{2}$ : PDF \#74-0521.

Table 4 Analytical results of the obtained titanium sample after the experiment for the magnesiothermic reduction of $\mathrm{TiCl}_{3}$.

a) Determined by X-ray fluorescence analysis (XRF), and the value excludes carbon and gaseous elements.

b) Average of top part and bottom part in the obtained titanium sample. 
table, titanium metal with a purity of more than $99 \%$ was successfully obtained under some conditions. In Exp. C, since a stainless steel reaction container was used instead of the titanium reaction container, the titanium sample obtained after the experiment was contaminated with iron, nickel, and chromium, which are derived from the composition of the stainless steel reaction container. Aluminum, as an impurity, is derived from $\mathrm{AlCl}_{3}$ that was not sufficiently removed by sublimation; thus, it remained in the reaction container. The reason for the retention of $\mathrm{AlCl}_{3}$ in some experiments is not clear and currently under investigation.

The yield of the titanium obtained after the reduction was $91 \%$ in Exp. E, where the reduction of $\mathrm{TiCl}_{3}$ proceeded sufficiently. The titanium yield obtained after Exp. D was $66 \%$, and it was lower than that in Exp. E since reduction of $\mathrm{TiCl}_{3}$ in the top part of the reaction container did not proceed sufficiently.

The microstructure of the titanium sample obtained after the experiment was observed by SEM. In Exp. A, titanium metal with a coral-like structure comprising primary particles with diameters of $1-5 \mu \mathrm{m}$ was obtained. Figure 8 (a) shows an SEM image of the titanium sample obtained in Exp. B. As compared with Exp. A, the neck of each primary particle in the titanium sample in Exp. B was larger. This result indicates that the sintering of the primary particles proceeded during the separation process for the reaction product $\mathrm{MgCl}_{2}$ and excess magnesium by vacuum distillation. The titanium metal obtained in Exp. C exhibited a microstructure similar to that in Exp. B. The titanium metal obtained in Exp. D and E [see Fig. 8(b)] exhibited a microstructure similar to that in Exp. A.

\subsection{Separation process by a combination of draining and vacuum distillation}

The changes in the sample temperature during the magnesiothermic reduction of $\mathrm{TiCl}_{3}$ in Exp. $\mathrm{X}$ and $\mathrm{Y}$ were identical to those in Exp. D and E [see Fig. 4(b)]. After the reduction of $\mathrm{TiCl}_{3}$ was complete, the outlet port was opened to drain the liquid reaction product $\mathrm{MgCl}_{2}$ and excess magnesium. Subsequently, the reaction product $\mathrm{MgCl}_{2}$ and excess magnesium that remained in the reaction container after the draining were removed by vacuum distillation. The changes in the sample temperature during the separation process for the $\mathrm{MgCl}_{2}$ and excess magnesium in Exp. Y are shown in Fig. 5(b). The sample temperature during the separation process steadily increased and reached $1273 \mathrm{~K}$ earlier than in Exp. B, although the masses of the charged $\mathrm{TiCl}_{3}$ and magnesium in Exp. Y were five times greater than those in Exp. B. This result reveals that most of the reaction product $\mathrm{MgCl}_{2}$ and excess magnesium had already been efficiently drained, and a small amount of the same that remained in the reaction container after the draining was evaporated and removed by vacuum distillation.

The titanium deposit recovered from the titanium reaction container after the experiment is shown in Fig. 9(a). As shown in this figure, the titanium deposit without $\mathrm{MgCl}_{2}$ and magnesium was obtained directly from the reaction container. The reaction product $\mathrm{MgCl}_{2}$ and the excess magnesium were recovered from the stainless steel tray [see Fig. 9(c)] and the stainless steel condenser [see Fig. 9(d)]. (a) Exp. B

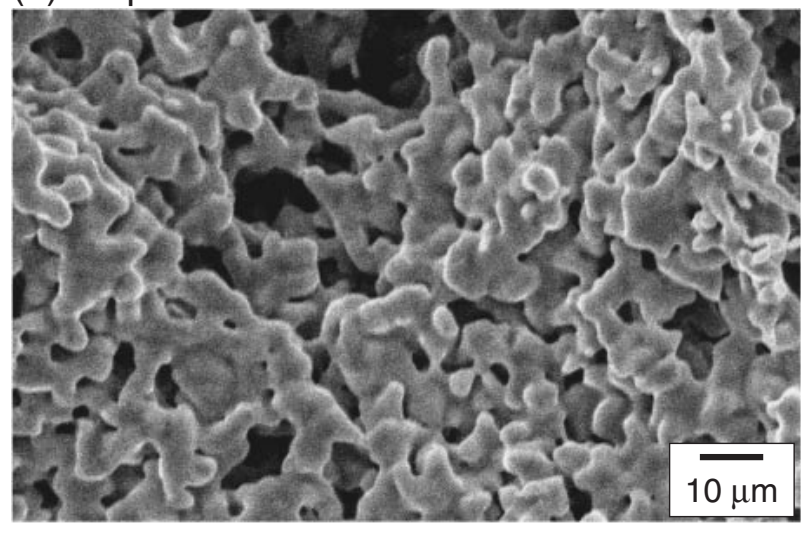

(b) Exp. E

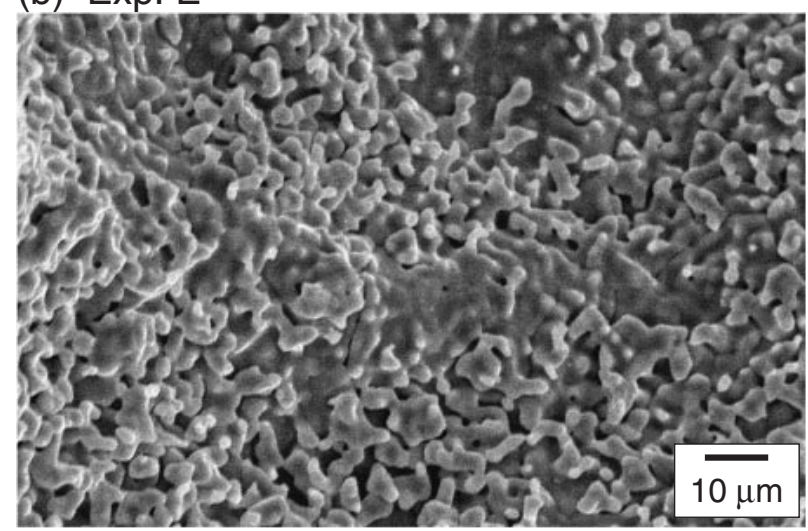

(c) Exp. Y

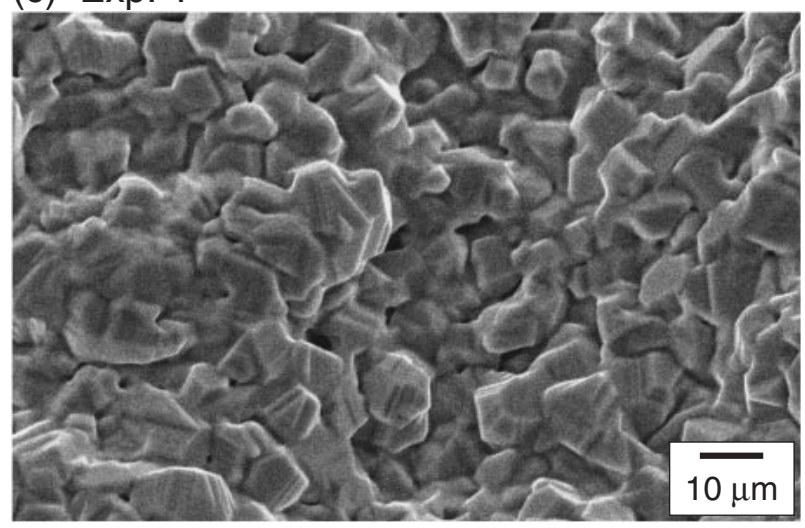

Fig. 8 Scanning electron micrographs of titanium deposit after the experiment for the magnesiothermic reduction of $\mathrm{TiCl}_{3}$ : (a) Exp. B, (b) Exp. E, (c) Exp. Y.

The XRD pattern of the deposit obtained after Exp. $\mathrm{Y}$ is shown in Fig. 7(d). From this figure, it can be seen that only $\alpha$-titanium was directly obtained without leaching. The analytical results of the obtained titanium samples after the experiment are listed in Table 4 . The yield was $82-87 \%$, and titanium with a purity of more than $99 \%$ was successfully obtained. An SEM image of the titanium deposit obtained in Exp. $\mathrm{Y}$ is shown in Fig. 8(c). A platy structure comprising primary particles, which were no longer spherical, and rugged primary particles were observed. The microstructure of the titanium in Exp. X was identical to that in Exp. Y. The mechanism of the change in the shape of the titanium primary particle is currently under investigation. 
(a) Obtained Ti deposit

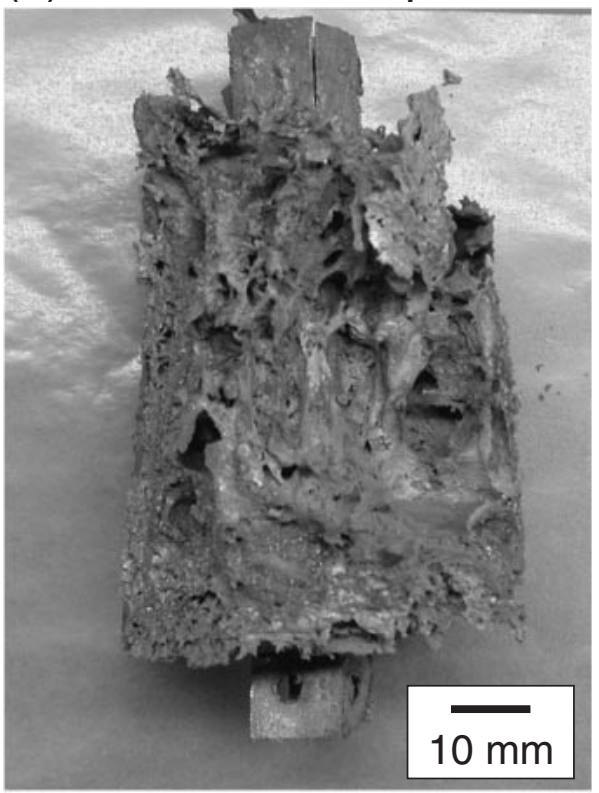

(c) Drained $\mathrm{Mg} / \mathrm{MgCl}_{2}$

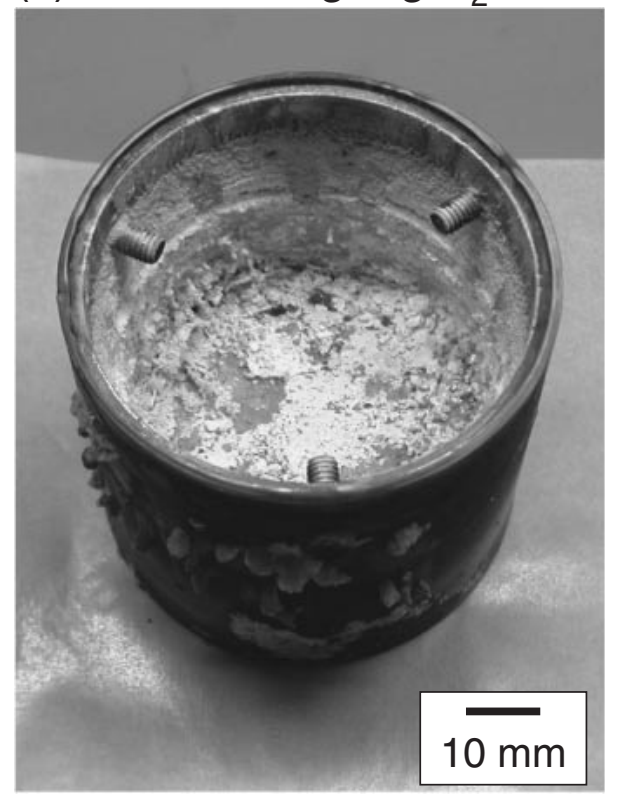

(b) Setup

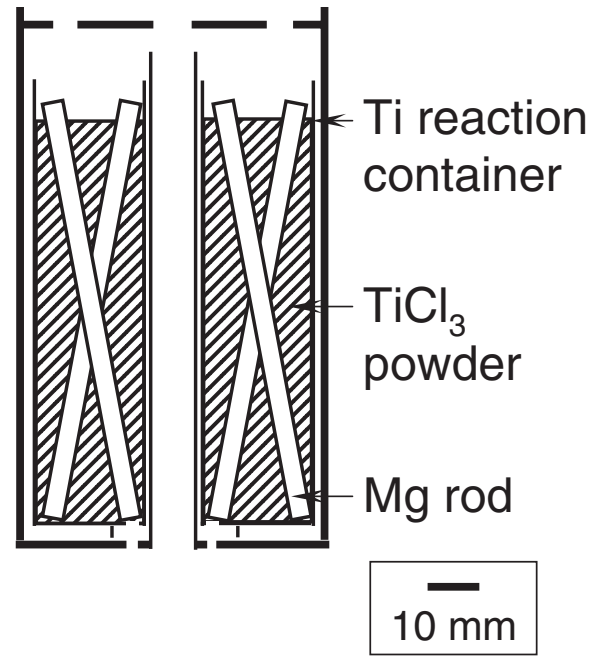

(d) Evaporated $\mathrm{Mg} / \mathrm{MgCl}_{2}$

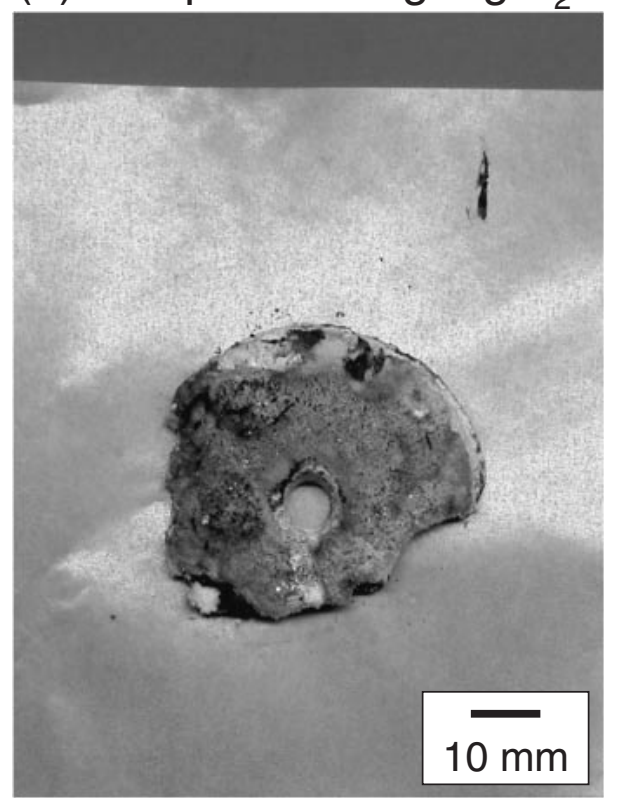

Fig. 9 (a) Photograph of the obtained titanium deposit after the experiment for the magnesiothermic reduction of $\mathrm{TiCl}_{3}$, (b) $\mathrm{schematic}$ illustration of the initial setup before the experiment, (c) photograph of drained $\mathrm{MgCl}_{2}$ and magnesium, (d) precipitate of $\mathrm{MgCl}_{2}$ and magnesium after evaporation (Exp. Y).

In this article, a high-speed and (semi-)continuous titanium production process by the magnesiothermic reduction of $\mathrm{TiCl}_{3}$ was discussed, and its feasibility was demonstrated. The process using $\mathrm{TiCl}_{2}$ is also scheduled to be discussed in another article. The authors are currently developing a process for producing $\mathrm{TiCl}_{x}$ from $\mathrm{TiCl}_{4}$ and an enrichment process of $\mathrm{TiCl}_{x}$ with the aim of establishing a high-speed semi-continuous titanium production process.

\section{Conclusions}

Fundamental research was conducted with the purpose of developing a new high-speed, semi-continuous titanium production process by subhalide reduction, and the feasibility of the process was demonstrated. Experiments on the magnesiothermic reduction of $\mathrm{TiCl}_{3}$ were carried out, and titanium with $99.5 \%$ purity was obtained. It was demonstrated that the reaction container made of titanium was applicable to the magnesiothermic reduction of $\mathrm{TiCl}_{3}$, and the reaction product $\mathrm{MgCl}_{2}$ and excess magnesium were shown to be removed efficiently by combining both draining and vacuum distillation.

\section{Acknowledgements}

The authors are grateful to Professors Masafumi Maeda 
and Yoshitaka Mitsuda of the University of Tokyo and Dr. Tetsuya Uda of Kyoto University for valuable discussions throughout this project. The authors also appreciate $\mathrm{Mr}$. Susumu Kosemura, Mr. Masanori Yamaguchi, and Mr. Yuichi Ono of Toho Titanium Co., Ltd., for valuable discussions and for providing the samples. This work was financially supported by a Grant-in-Aid for Scientific Research (A) from the Ministry of Education, Culture, Sports, Science and Technology, Japan (MEXT, Project ID. \#15686031). A part of this research includes the result of the "Development of Electrochemical Reduction Process for Oxide Nuclear Fuel" program conducted by the Central Research Institute of the Electric Power Industry, which is financially supported by the MEXT. One of the authors, O. Takeda, is grateful for the financial support provided by the Grant for the 21st Century COE Program "Human-friendly Materials based on Chemistry" from the MEXT.

\section{REFERENCES}

1) W. Kroll: Tr. Electrochem. Soc. 78 (1940) 35-47.

2) A. Moriya and A. Kanai: Shigen-to-Sozai 109 (1993) 1164-1169.

3) T. Fukuyama, M. Koizumi, M. Hanaki and S. Kosemura: Shigen-toSozai 109 (1993) 1157-1163.

4) S. Nakamura: Industrial Rare Metals, (Arumu Publish, Tokyo, 2004) pp. 52-55.

5) Z. Chen, D. J. Fray and T. W. Farthing: Nature 407 (2000) 361-364.

6) K. Ono and R. O. Suzuki: JOM (Journal of Metals) 54 February (2002)
59-61.

7) T. Abiko, I. Park and T. H. Okabe: Proc. 10th World Conference on Titanium, Ti 2003 (Hamburg, July 13-18, 2003) pp. 253-260.

8) M. V. Ginatta: Proc. 10th World Conference on Titanium, Ti 2003 (Hamburg, July 13-18, 2003) pp. 237-244.

9) G. R. B. Elliott: JOM (Journal of Metals) 50 September (1998) 48-49.

10) G. Crowley: Adv. Mater. \& Processes 161 November (2003) 25-27.

11) S. Takaya, M. Tsumura, A. Fuwa, E. Fukasawa and N. Nakahara: Abstracts of the Mining and Materials Processing Institute of Japan (MMIJ) 2005 Spring Meeting II (2005) pp. 87-88.

12) A. Fuwa and S. Takaya: JOM (Journal of Metals) 57 October (2005) 56-60.

13) O. Takeda and T. H. Okabe: Abstracts of EUCHEM 2004 Molten Salts Conference (Poland, June 20-25, 2004) p. 186.

14) O. Takeda and T. H. Okabe: Abstracts of the Mining and Materials Processing Institute of Japan (MMIJ) 2004 Autumn Meeting II (2004) pp. 329-330.

15) O. Takeda and T. H. Okabe: Proc. 2005 TMS Annual Meeting (San Francisco, California, Feb. 13-17, 2005) pp. 1139-1144.

16) I. Barin: Thermochemical Data of Pure Substances, (VCH Verlagsgesellschaft mbH, Weinheim, Germany, 1989) pp. 1531-1533.

17) M. Nakahara: Dictionary of Inorganic Compounds \& Complexes, (Koudansya, Tokyo, 1997) p. 87.

18) S. Nagasaki et al.: Kinzoku Data Book, 3rd ed., (Japan Inst. Metals, Maruzen, Tokyo, 1993) pp. 1-11.

19) N. Okudaira: Titanium•Zirconium 12 (1963) 179-200.

20) K. Komarek and P. Herasymenko: J. Electrochem. Soc. 105 (1958) 210-215.

21) S. Shimosaki and M. Kuramoto: Kagaku Kogaku Ronbunshu 21 (1995) 740-745.

22) T. Noda: J. Mining Inst. Jpn. 84 (1968) 967-981. 